\title{
How Much for the Child?
}

\author{
Christian Barry • Gerhard Øverland
}

Accepted: 7 November 2011

(C) Springer Science+Business Media B.V. 2011

\begin{abstract}
In this paper we explore what sacrifices you are morally required to make to save a child who is about to die in front of you. It has been argued that you would have very demanding duties to save such a child (or any adult who is in similar circumstance through no fault of their own, for that matter), and some examples have been presented to make this claim seem intuitively correct. Against this, we argue that you do not in general have a moral requirement to bear more than moderate cost to save even a child who is just in front of you. Moreover, we explain why you have a much more demanding moral requirement in certain cases by appealing to the notions of undue risk and cost sharing.
\end{abstract}

Keywords Duties of assistance $\cdot$ Global poverty $\cdot$ Peter Singer

\section{Introduction}

Our world is characterized by severe and widespread poverty - shortfalls that persons suffer in their health, civic status, or standard of living relative to the basic requirements of human beings. Among the roughly 6.8 billion human beings currently alive, 3.08 billion people45 per cent of the world's population-live below the $\$ 2.50$ per day poverty line, about 1.02 billion are undernourished, 884 million lack access to safe drinking water, 2.5 billion lack adequate sanitation, and 1.5 billion have no electricity (Food and Agriculture Organization 2009; World Health Organization and UNICEF 2010; International Energy Agency 2011). Children are among those most affected by poverty. 218 million of them are trapped in child labour, of which 126 million are in hazardous work, 5.7 are engaged in

C. Barry $(\bowtie)$

Christian Barry, School of Philosophy, RSSS, Australian National University,

Canberra ACT 0200, Australia

e-mail: christian.barry@anu.edu.au

G. Øverland

Centre for the Study of Mind in Nature, University of Oslo, Oslo, Norway

G. Øverland

Centre for Applied Philosophy and Public Ethics, Charles Sturt University, Canberra, Australia 
forced or bonded labor, and many thousands of children die each day of poverty-related causes (UNICEF 2006). ${ }^{1}$ These facts are generally held to be not merely unfortunate or regrettable, but morally unacceptable. When considering such facts it seems obvious that affluent people are morally required to bear some cost to alleviate such poverty, provided it is within their power to do so. But just how much cost the affluent are morally required to bear to address such poverty is a matter of great controversy. We shall call the amount of cost that the affluent are morally required to bear to assist others in great need required cost.

One influential line of argument, developed by Peter Singer and Peter Unger (the Singer-Unger line), explores the issue of principles for determining required cost by examining simple cases in which an affluent person can save a child in front of them at some cost, and drawing inferences from our judgments about these cases to judgments about how we ought to view the relation of affluent people to the global poor more generally. Singer and Unger appeal to intuitions that the required cost of saving a child that is at risk of dying right in front of you is very high, and proceed by arguing that there are no relevant differences between your relation to this child and your relation to children dying of poverty-related causes throughout the world. Consequently, it is inferred that the required cost for ordinary affluent people to address the needs of poor children throughout the world is very high, and that they must for this reason eliminate much of their ordinary expenditure to meet this demand.

Critics of the Singer-Unger line have typically tried to establish that the analogical arguments on which their conclusions are based are flawed, since there are significant differences between children dying of poverty related causes across the world and children dying right in front of you. Here we shall take a different tack. We seek to undermine the assumption - so far unquestioned by critics of the Singer-Unger line - that the required cost of saving a child that is dying right in front of you is very high. We defend a principleModerate - according to which you are ordinarily required to take on only moderate cost to save such a child. There are some cases in which the required cost is much higherincluding some of the cases appealed to by Singer and Unger in their seminal work-but we show that these cases are special by appealing to the notions of undue risk and cost sharing, and argue that they are therefore different from ordinary cases involving children in faraway lands. We note that even Moderate would demand a great deal more of the affluent than they currently devote to addressing global poverty so long as it is assumed there are feasible and effective ways of their doing so.

\section{Preliminaries}

We shall focus here on discussing the required cost of saving children in need. This is not because we think there is necessarily any difference between the required cost of saving healthy children (provided that they are not very young) and of saving healthy adults (provided that they are not very old). We focus on the required cost of saving children partly because the Singer-Unger line has typically been framed in terms of saving children.

More importantly, we do so because there is always some possibility that adults, unlike young children, can be held partially or fully responsible for being in a position where they

\footnotetext{
${ }^{1}$ Child Labour is defined by the ILO as "work that is harmful to children's physical and mental development." See http://www.ilo.org/ipec/Campaignandadvocacy/Youthinaction/C182-Youth-orientated/ C182Youth_Background/lang-en/index.htm. Accessed 7 September, 2011.
} 
need help, which many think should reduce the required cost of saving them. Moreover, since some people may believe that the required cost to save a child is higher than that to save an adult, arguments that show that the required cost to save a child is not very high suffice also to show that the same is true with respect to saving adults.

In all of the cases that we shall examine you are the only one who can save the child. However, you have not contributed to the child's plight, for example by having pushed the child into the pond or coaxed him into wading into it. Had you done so, it would be fairly uncontroversial that the required cost to you of saving the child would be quite high. Moreover, the child is a total stranger to you, and so is his family: you have not promised anyone that you will look after him, and do not occupy a specific role that requires you to save children or others in need and thus have no special or associative duties to the child. If you had such duties, it would again seem fairly uncontroversial that the required cost for you to save him would be quite high. ${ }^{2}$

If it could be established that the required cost of saving a particular child in front of you is very high, we might also be led to conclude that the required cost of saving poor children throughout the word is also very high. According to Peter Singer, for instance, "we have an obligation to help those in absolute poverty that is no less strong than our obligation to rescue a drowning child from a pond" (Singer 1993, 230). Given that there are many children in the world that we can help who are just as vulnerable as the child in the pond, Singer concludes "When we spend our surplus on concerts or fashionable shoes, on fine dining and good wines, or on holidays in faraway lands ... we are doing something wrong" (Singer 2009, 19).

It is, of course, possible to discount the importance of people's intuitive responses to cases - especially some artificial cases involving children in ponds - but we won't question this method here. Throughout this article we shall generally confine ourselves to arguing, as Singer and Unger do, by appealing to people's intuitive judgments about particular cases and bringing these judgments to bear on our understanding of our duties in other cases.

It is also possible to take issue with the pond analogy itself. One can, for example, accept that the required cost of saving a child that is drowning in front of you is very high but deny that the required cost of lowering the poverty-related death toll of children worldwide is anywhere near as high. Indeed, critics of the Singer-Unger line have typically appealed to factors that distinguish the moral relations between the passer-by and the child from that of ordinary affluent people and the global poor (Cf. Miller 2004; Schmidtz 2000; Wenar 2003). That is, they have not challenged the premise that when you are the only one who can save a particular child in front of you, the required cost to save him based on merely being able to save him is very high. Rather, they attempt to explain why affluent people in the developed world are nevertheless not morally required to make comparable sacrifices to help the global poor by indicating how our relations to these poor people are different in morally significant ways from our relation to a child in front of us.

We think it unlikely that these strategies against the Singer-Unger line will succeed. If we had an unqualified moral requirement to bear a very high cost to save a child in front of us, we think it would be difficult to avoid the conclusion that the required cost of addressing global poverty is also very high, even if not quite as high. But we will not argue for this here. Instead, we shall argue that unless certain conditions are satisfied, the required cost of saving the life of a child in front of you is nowhere near as high as the Singer-Unger line maintains. We will argue that the particular examples that might lead one to adopt the Singer-Unger line have intuitive force only because of other (contingent and unusual) factors that are present in them. In comparable examples in which these factors are not

\footnotetext{
$\overline{2 \text { Just how high the required cost }}$ would be depends on the content of the special duties.
} 
present, people will not ordinarily maintain that the agent who can save the child has such duties. We conclude that, ordinarily, the required cost of saving a child in front of you from imminent death is relatively moderate.

\section{Assistance Principles}

Duties to assist have been frequently appealed to in philosophical arguments regarding the responsibilities of affluent people to address global poverty at least since Peter Singer's seminal article 'Famine, Affluence, and Morality' (Singer 1972). In that work, Singer argued that we have duties to assist the global poor by using the analogy of the person passing a shallow pond where a child is about to drown. Just as the person walking by the pond is morally required to make the necessary sacrifice to save the child, so too the affluent are required to assist people in great need throughout the world. Singer goes on to assert specific principles of assistance, which determine the level of required cost for agents to help those in great need.

As Garrett Cullity has pointed out, Singer's analogical arguments are "subsumptive" in form (Cullity 2004, 12-14). That is, Singer conceives of the task of justifying particular moral judgments (in his work on poverty, at least) as a matter of postulating general principles that these particular judgments can be viewed as expressing. And Singer's arguments are potentially quite radical precisely because they have this form. His strategy is to show that some principle of assistance that best explains a particular moral judgment in which we have a great deal of confidence, such as that the required cost of saving a child in the pond case is very high, would entail that we revise a great many of our other moral judgments. One such judgment that we would need to revise is that the required cost of addressing global poverty is not very high at all.

\section{Singer's Three Formulations}

Singer has given three different formulations of the principle of assistance, all of which assert a very high level of required cost for prospective assistors. Two of these formulations appear in 'Famine, Affluence, and Morality', and the third appears in his recent book The Life You Can Save (Singer 2009). Singer defines his three principles of assistance as follows (the tags are ours):

$S A P_{1}$ : "if it is in our power to prevent something bad from happening, without thereby sacrificing anything of comparable moral importance, we ought, morally, to do it" (Singer 1972, 231).

$\mathrm{SAP}_{2}$ : "if it is in our power to prevent something very bad from happening, without thereby sacrificing anything morally significant, we ought, morally, to do it" (Singer 1972, 231).

$\mathrm{SAP}_{3}$ : "if it is in your power to prevent something bad from happening, without sacrificing anything nearly as important, it is wrong not to do so" (Singer 2009, 15).

All three of these principles would explain our reaction to the pond case, and if accepted, each would also seem to entail that the required cost of assisting the global poor is very high. Let us therefore take a look at each of them. 
$S A P_{1}$ : if it is in our power to prevent something bad from happening, without thereby sacrificing anything of comparable moral importance, we ought, morally, to do it.

This is an extremely demanding principle. By "without sacrificing anything of comparable moral importance" Singer means "without causing anything else comparably bad to happen, or doing something that is wrong in itself, or failing to promote some moral good, comparable in significance to the bad thing that we can prevent" (Singer 1972, 231). Surprisingly, he seems to think that this is not a very controversial principle, as he compares it to a principle that requires that we promote what is good and prevent what is bad (ibid.). However, this principle is very controversial and almost no one seems to think that anything close to it should be accepted. When you are faced with a drowning child, you should wade out if doing so will only cost you getting your suit wet, but few seem to believe that you would be required to sacrifice everything short of your life to save the child. Making such a sacrifice might be heroic and praiseworthy, but would far exceed the required cost of saving the child according to most moral outlooks. Note that your life, and perhaps some other very serious harm, is pretty much the only cost that could be deemed comparably as bad as the death of a child, impartially considered.

Singer's second formulation is presented as more acceptable to those who would believe $S A P_{1}$ to be too demanding.

$\mathrm{SAP}_{2}$ : if it is in our power to prevent something very bad from happening, without thereby sacrificing anything morally significant, we ought, morally, to do it.

We think this is Singer's most obscure formulation, since it is difficult to understand what it really implies about required cost. Why does he say that what is significant should be morally significant? What we are interested in, after all, is whether a particular agent ought to make a particular sacrifice to assist another person in need. If you are asked to sell your apartment to save a sick child, that surely is a significant sacrifice to ask you to bear, but is it morally significant? And is the significance of giving up your apartment moral in a way that giving up $\$ 100$ would not be?

What would make a sacrifice morally significant? One proposal would be that as long as the agent voluntarily makes such sacrifices at his own expense, no sacrifice would be morally significant. Perhaps costs imposed on third parties would be morally significant. But this way of interpreting the idea of morally significant costs would make no sense when applied to $\mathrm{SAP}_{2}$, given the role Singer wants this principle to play. Alternatively, one could suggest that there are things you do not need to sacrifice to save the lives of others, because there are things that are morally significant. But that is not very helpful either. We would simply be weighing what is at stake for the victim against what would need to be sacrificed by the prospective assistor, and name the point at which agent would no longer be required to make the sacrifice 'morally significant'. What we want to know, however, is what the required cost of assisting is and, correspondingly, what sacrifices would exceed it.

According to Singer, an application of his second formulation would be as follows:

if I am walking past a shallow pond and see a child drowning in it, I ought to wade in and pull the child out. This will mean getting my clothes muddy, but this is insignificant, while the death of the child would presumably be a very bad thing (Singer 1972, 231). 
It is true that $\mathrm{SAP}_{2}$ would require the agent to save the child under these circumstances. But it would follow from pretty much any conceivable formulation of a principle of assistance, given that the costs involved in this case are so very small and the benefits of assisting are so large.

At some point Singer says that, when we "buy new clothes not to keep ourselves warm but to look 'well-dressed' we are not providing for any important need" (Singer 1972, 235). One might therefore interpret morally significant sacrifices as those involving the deprivation of an important need. Indeed, Singer seems to suggest this as he continues: "we would not be sacrificing anything significant if we were to continue to wear our old clothes, and give the money to famine relief" (Singer 1972, 235). Substituting "morally significant" with "important need" would be a real improvement in clarity in the formulation of $\mathrm{SAP}_{2}$. But is such a principle plausible? Not many people are busy meeting important needs in Singer's sense. Clearly we do need shelter, food, and health care. But most relatively affluent people could easily sell their dwelling and move into a very basic one or two bedroom apartment without having to leave these important needs unmet. But that doing this is morally required is far from intuitively obvious.

Let us turn, then, to Singer's third formulation of his assistance principle.

$S A P_{3}$ : if it is in your power to prevent something bad from happening, without sacrificing anything nearly as important, it is wrong not to do so.

What does this principle mean? Often, what is not nearly as important as something else is not very important at all, such as getting one's clothes muddy. Singer defends in his recent book what he calls a reasonable standard of giving (RSG) for the affluent to address global poverty. This standard demands only that those earning between $\$ U S 105,000$ and $\$ 148,000$ per year donate $5 \%$ of their income for this purpose, and that those earning above this level provide a progressively larger portion of any income they earn above this level (Singer 2009, 179). This standard is, of course, securely within what is demanded by $\mathrm{SAP}_{3}$, but we also think that the level of sacrifice of the RSG would be required by much less demanding principles of assistance, such as the moderate principle of assistance we introduce and defend below. ${ }^{3}$ And of course all of Singer's principles are much more demanding than the RSG. Just to give one example, to give up $50 \%$ of your $\$$ US 105,000 income is very unlikely to cost you anything nearly as important as the life of a child.

Just how demanding is $\mathrm{SAP}_{3}$ ? Much depends upon how the notion of relative importance is understood. Singer does not give explicit guidance on how this notion is to be understood, but rather leaves it up to his readers to decide on the basis of their intuition (Singer 2009, 17). One reasonable way of thinking about the notion of relative importance is the following. Imagine some person $\mathrm{C}$, who can choose to prevent either person A from bearing some cost $\mathrm{X}$ or person $\mathrm{B}$ from bearing some cost $\mathrm{Y}$ (but not both). If, all else being equal, they ought to prevent $\mathrm{A}$ from bearing cost $\mathrm{X}$, then this cost is of greater relative importance than cost $\mathrm{Y}$ is to B. If $\mathrm{C}$ is faced with the choice of saving A's life or B's hand, then all other things being equal he ought to save A's life. This alone does not show that the $\mathrm{SAP}_{3}$ would demand that B sacrifice his hand to save A's life. It might be argued that B's hand is nearly as important as A's life is. This claim seems hard to sustain. All things being equal, if $\mathrm{C}$ is faced with the choice of saving A's life or one of B's hands and one hand each

\footnotetext{
${ }^{3}$ That is, provided that Singer's empirical assumptions about the potential of assistance to alleviate poverty are sound.
} 
of several other people, it seems that he ought clearly to save A's life, indicating that a hand is not nearly as important as a life. $\mathrm{SAP}_{3}$ is therefore very demanding indeed.

It would appear then that even Singer's least demanding version of the principle of assistance $-\mathrm{SAP}_{3}$ - is quite demanding. Are we morally required to sacrifice our hands or limbs to save the life of a child in front of us? For many —including us - who do not think that this would be required of us, the $\mathrm{SAP}_{3}$ will be seem overly demanding.

\section{Less Demanding Principles of Assistance}

Liam Murphy argues that the optimizing principle of beneficence $\left(\mathrm{SAP}_{1}\right.$ in addition to a general moral requirement to promote the good) imposes its demands unfairly in situations of partial compliance (Murphy 2000). If an agent is complying with the optimizing principle, but others are not, she not only has to do her own fair share, but she has to take on as much of the shares of the non-complying others as is optimal as well. This is unfair, according to Murphy, who in redress suggests a "compliance condition", which states, "the demands on a complying person should not exceed what they would be under full compliance with the principle" (Murphy 2000, 7).

This is not the place to assess fully Murphy's compliance condition (for a good critical discussion see Arneson 2004, 35-9) but two things about this approach should be noted. First, if some people need assistance it seems implausible to say that a particular agent's required cost depends on what others do-except, of course, in the sense that if they indeed do what they ought to, the necessary cost for the agent will be lower because less would be left for him to do. The fairness consideration only seems to concern fairness between prospective assistors. Each person's level of required cost, by contrast, depends on the costs to the agent weighed up against the needs of the person in need of assistance. Murphy's principle implies that if enough people fail to do their fair share, the necessary cost to an agent of saving someone may very well exceed the required cost. The agent would therefore lack a duty to assist the person in need. But unfairness between the complying and non-complying should not be confused with the required cost of each agent to assist those in need. ${ }^{4}$ It may be unfair that others do not act on their moral reasons, leaving you with the whole burden (within the limit of what is demanded by individuals), but this is orthogonal to the issue of the required cost of you to save the child.

Second, Murphy's approach doesn't challenge the optimizing principle. On his view it is still the case that a solitary individual would have to make severe sacrifices to save another person's life according to any of the SAPs. Murphy's proposal is conditional on the presence of others, and may seem designed to bring relief for affluent individuals faced with global poverty. Murphy's proposal makes no attempt to limit the demands on a single individual who is not surrounded by others but is in a position to help the child.

Bear in mind that in the initial pond case, all that is at stake for the passer-by is getting his clothes muddy and being late for a meeting. There is no need to appeal to anything nearly as demanding as any of Singer's assistance principles to explain the judgment that the agent acts very wrongly if he fails to rescue the child and continues on his way. There are various other much less demanding principles that would explain this. The cost you are asked to bear-getting your clothes wet and coming late to a meeting-seems quite

\footnotetext{
${ }^{4}$ A similar point is made by Arneson (Arneson 2004, 37) who writes "The mere fact of non-compliance by some does not automatically set an upper limit on the amount of sacrifice it is reasonable to demand of others who can provide cost-effective aid."
} 
minimal indeed. Hence, another principle that would explain this judgment would be what we might call the Minimal Assistance Principle (hereafter simply Minimal). Minimal states that:

Minimal: if you can prevent something very bad from happening to another person at minimal cost to yourself (relative to what is at stake for the other person) then you ought to do it.

We formulate this principle to make it clear how little is shown by Singer's original pond case on its own, given the subsumptive and analogical form of Singer's argument. But while all the SAPs seem too demanding, Minimal may seem to demand too little. We might, for instance, envisage that the meeting is quite important for the person, in which case saving the child would not have been required according to Minimal. We might also consider the question of sacrificing body parts. Assuming that hair is part of your body, to be asked to have your hair cut to save the child would be to ask you to make a minimal sacrifice (assuming you do not want it to be cut), as would be to ask you to suffer a kick in the leg. It seems clear that you are morally required to make such a sacrifice to save a child. But to ask you to bear only a minimal cost is to ask you to make a very small, almost negligible sacrifice. And if that is all that we can morally require, the principle seems to demand too little. When something very bad is at stake for others and the required cost to you of helping them avert it is not so negligible, you ought to do so, at least according to most moral outlooks.

Intuitively, it doesn't seem too demanding to ask a person to shoulder moderate cost to prevent something that is really very bad from happening to another person. While having your hair cut could be a minimal cost, to ask you to sacrifice a finger seems better described as moderate. Loosing a finger is not a negligible loss, but compared to what is at stake it is nevertheless relatively moderate. Yet, some (and perhaps many) would think you ought to sacrifice a finger to save a child, unless perhaps you are a pianist or rely for some other reason on having all of your fingers to ply your trade or to do what you love most. A moderate principle of assistance — we'll call it Moderate — seems more plausible.

Moderate: if you can prevent something very bad from happening to another person at moderate cost to yourself (relative to what is at stake for the other person) then you ought to do it. 5

The cost in question could be measured in units of welfare. We make certain simplifying assumptions, however, which are that all people will be on similar welfare levels when they have the same access to resources, and that to give up a certain material resource unit, whether wealth or body parts, will constitute a similar setback in welfare.

In all our cases, what is at stake for the child is his or her life. How much cost is moderate cost relative to the life of a child? We do not think there is any precise amount to be found here. It is not the case that relative to the death of child there is an exact amount of cost that others ought to bear to prevent it. However, we do think the ordinary meaning of moderate gives a fairly good guide with regard to the required cost this principle would demand.

\footnotetext{
${ }^{5}$ Compare Scanlon: "If you are presented with a situation in which you can prevent something very bad from happening, or alleviate someone's dire plight, by making only a slight (or even moderate) sacrifice, then it would be wrong not to do so" (Scanlon 1998, 224).
} 
Do you have to give up moderate cost both when it comes to body parts and wealth? Or, could it be that while you would be required to give up moderate cost when it comes to wealth you would not be required to give up moderate cost when it comes to body parts? Since we think the ultimate cost-unit is welfare, we suggest that the demand is the same for both types of sacrifice. Any person would be required to give up a moderate amount of welfare units to save the life of a child, and this cost could be represented in wealth as well as in body parts. Of course, people may vary with regard to how they translate the loss of resources and body parts into welfare units. We have therefore made the simplifying assumption that they translate body parts and resources into units of welfare equally.

\section{Self-Sacrifice}

To evaluate Moderate, let us start by considering cases in which Moderate seems to fair better on intuitive grounds than any of the SAPs. It seems to us pretty straightforward that all SAPs are implausible when we consider that they require the sacrifice of large body parts to save a child. Imagine, for instance, that when wading into the pond you will loose a leg. Perhaps a crocodile or some other predator will snatch it away. Would you still have a duty to rescue the child? We are pretty confident that few will find acceptable what all the SAPs seem to entail: that you would have to give up a leg in this case. To give up a leg is clearly not to sacrifice "anything of comparable moral importance", nor is it to sacrifice "anything nearly as important", insofar as we can make sense of this notion. Hence $\mathrm{SAP}_{1}$ and $\mathrm{SAP}_{3}$ would require us to give up a leg to save a child. Giving up a leg could, however, be called sacrificing something "morally significant", and $\mathrm{SAP}_{2}$ could accordingly not in fact require that we make this sacrifice. Whether or not $\mathrm{SAP}_{2}$ would require the sacrifice of a leg would depend on how we are supposed to make sense of when something is morally significant, and we have no clear idea about how to elucidate and apply this notion.

Clearly, wading into a pond that has a crocodile in it might involve further risks to life and limb beyond one leg, and this may influence judgments about this case. So suppose that you are the only one who can save a child in front of you and there is no additional risk involved in having to give up a limb. There could, for instance, be a need for you to sacrifice a leg to create a lifesaving serum that would be necessary to save a child from a particular new disease. You happen to be the only one that has the right physical condition. Would you be morally required to sacrifice your limb? Consider:

You and the Deserted Hospital: You are traveling with your camel through a deserted area when you come upon a hospital. A well-known surgeon and a dying child are the only people present. The child can only be saved if given a serum made out of a human limb within $1 \mathrm{~h}$. You are the only person around that can sacrifice the limb so that the surgeon can produce the serum and save the child.

Would you fail to discharge a moral duty if you decline to make this sacrifice? People may have different reactions to this case, but it seems pretty obvious to us that that you would not. Perhaps it depends on the importance to you of the limb that you are required to give up, but we do not think so. And, clearly, the number of people that would agree with Singer that you would be morally required to sacrifice your limb in this case would be considerably fewer than would agree that you should muddy your clothes to save the child, as in his original pond case. Furthermore, it does not appear to be permissible to impose more than moderate cost to enforce duties to assist. While it might be permissible to force 
you to lose a finger to save a child in front of you, enforcing the loss of a limb on you to save the child doesn't seem to be permissible at all.

To conclude, how much self-sacrifice are you morally required to make to save the child? Nothing close to what all three of Singer's assistance principles would seem to demand of you.

\section{Money and Wealth}

So far we have only indicated some problems with the SAPs regarding having to make a specific type of sacrifice - loss of body parts - to save a child. One might think, however, that our judgments about these cases have to do with the special value of bodily integrity, and that one or more of the SAPs apply convincingly to cases where we are instead considering whether to make significant sacrifices in money and wealth to save a child's life.

To show that Moderate is too weak to account for our intuitions about duties to assist, supporters of more demanding principles of assistance must appeal to further cases where we have strong intuitions that agents must take on relatively quite large costs to prevent very bad things from happening. Surprisingly, no such case was presented in 'Famine, Affluence, and Morality'. However, one such case, which Singer puts front-and-centre in his argument for $\mathrm{SAP}_{3}$ in his latest book, is Bob's Bugatti, a case imagined by Peter Unger (Unger 1996, 136). Its essential features are the following:

Bob's Bugatti: Bob, who has most of his retirement savings invested in a Bugatti, is confronted with the choice of redirecting a railway trolley by throwing a switch in order to save a child which will result in the destruction of his Bugatti because it has accidentally been placed on the side spur of the line, or he might leave the switch as it stands so that his Bugatti remains in mint condition, which will result in the child's death.

It appears that Bob has a duty to sacrifice his Bugatti, and Singer informs us that in his experience "people almost always respond that Bob acted badly when he did not throw the switch and destroy his most cherished and valuable possession, thereby sacrificing his hope of a financially secure retirement" (Singer 2009, 14).

We are sure that Singer has correctly represented the intuitions of people to whom he has presented the case. We also agree Bob ought to turn the switch. We don't think, however, that it is correct to infer from this that "when prompted to think in concrete terms, about real individuals, most of us consider it obligatory to lessen the serious suffering of innocent others, even at some cost (or even at high cost) to ourselves" (Singer 2009, 15). Consider the following case:

Bob's Internet Banking: Bob is sitting in his remote house doing some Internet banking. Unbeknownst to his only neighbors (the Smiths), he can see and hear them through the open door on the veranda. He notices that they are discussing the state of their terminally sick child, Jimmy, who is lying on a bed between them. They urgently need a new and expensive treatment to cure Jimmy. They therefore need to get a helicopter to bring their son to a private hospital far away. They live in a society that has no universal health coverage. They cannot afford the helicopter service, let alone the operation, themselves, nor are they able to finance it or acquire the funds 
from relatives and friends. Bob understands that he can transfer the money for the helicopter service and the operation with a click of his mouse (he already has the Smith's bank account listed). Clicking over the money would save Jimmy, but most of Bob's savings for retirement would be gone. Bob decides not to click the mouse.

Does Bob act wrongly in this case? We do not think so, and a great many people seem to agree. We may pity Jimmy Smith, and praise Bob for his generosity if he were to transfer the funds. But we do not seem to think that Bob would violate a moral requirement if he did not click the mouse to make the transfer - this exceeds the required cost for him of saving Jimmy, and he therefore lacks a duty to do so. What should we make of our judgments about these cases?

One strategy that Singer and Unger have employed when confronted by conflicts in moral judgments about cases that share important features is to appeal to psychological factors that, they argue, ought to be viewed as introducing "distortions" into our moral thinking about certain kinds of cases. ${ }^{6}$ These distorting factors, many of which are detailed in chapter four of Singer's The Life You Can Save, do not appear to be present in Bob's Internet Banking. Jimmy Smith is an identifiable victim (Singer 2009, 48-51), and our emotions are likely to be excited by his fate (Singer 2009, 53), yet it does not seem to alter our judgment of Bob's behavior. Further, we have no reason to believe that Bob's giving this money to the Smiths would be futile (Singer 2009, 55-56), counterproductive, or harmful - we might imagine that the hospital is so sure about success that they will give the money back if it is unsuccessful. Nor, apparently, is this a case where we are stumbling because of so-called "bystander effect" (Singer 2009, 57), since Bob has sound evidence (the Smiths are very trustworthy people who have explored every available option to save their child) that if he doesn't help the family, no one will, and that Jimmy will die.

It is true that Jimmy Smith is not uniquely dependent on Bob. Many other people could, by hypothesis, step in and provide the required money. It is just that no one will choose to do so. But Singer and Unger both agree that unique dependency is not morally significant (Singer 2007, 23, 31). If they were, their analogical argument from the pond case to our duties toward the global poor would clearly fail, since the global poor are not uniquely dependent on particular affluent individuals.

In Bob's Internet Banking, $\mathrm{SAP}_{1}$ and $\mathrm{SAP}_{3}$ fail to explain our judgment that Bob does not fail in any duty to the child when he does not transfer most of his retirement savings. As for $\mathrm{SAP}_{1}$ : Bob's savings for retirement are clearly not of comparable moral importance to the life of the child. As for $\mathrm{SAP}_{3}$ : all else being equal, if $\mathrm{C}$ were faced with the choice of saving Bob's money from destruction and Jimmy from premature death, she would act very wrongly indeed if she saved Bob's money. Hence, Bob's savings for retirement are not nearly as important as the life of a child. ${ }^{7}$

\section{Undue Risk and Cost Sharing}

So far, however, we don't have any reason to prefer Moderate to the three SAPs. In one case-Bob's Bugatti-we believe that Bob must make a sacrifice that appears to be beyond what Moderate would demand and in the other case-Bob's Internet Banking — we believe

\footnotetext{
${ }^{6}$ Unger writes: "Our intuitions on very many cases, both hypothetical and even actual, do nothing toward reflecting these Values, as they're produced by powerfully Distortional Mental Tendencies that prevent us from responding in line with the Values". (Unger 1996, 173-5)

${ }^{7}$ As for $\mathrm{SAP}_{2}$ : Bob's savings for retirement could be regarded as morally significant, and that is because it is more than required, more than moderate.
} 
that Bob is not required to make the sacrifice that the SAP seems to demand. However, we believe that there are other factors that can explain our judgments in Bob's Bugatti. While people do not in general have duties to make large sacrifices, relative to what they have, to prevent bad things from happening to other people to whom they lack special or associative duties, agents may be required to make such sacrifices under special circumstances. In particular, such sacrifices may be required of those who have exposed their assets to undue risk. We also think this to be true where the agent would be required initially to bear the cost of her sacrifice, but where others would be required to step in and compensate her for her costly preventive action afterwards.

\subsection{Undue Risk}

Note that in Unger's original case, it is pretty ridiculous of Bob to have invested nearly all of his assets in a Bugatti, use the repository of his savings to engage in the risky business of driving, and then leave it parked outside. Perhaps he has not wronged anyone by investing his savings in this way, but he has acted very imprudently, exposing himself to undue risk of serious loss. Cars are easily damaged, expensive cars are very attractive targets for theft, and are of little use value relative to other material assets such as dwellings. It may for that reason plausibly be argued that he has no right to protect his savings, thus exposed, at the cost of the child's life.

In addition to having acted imprudently, it might also be argued that it is unfair of Bob to drive around in such expensive cars. Drivers of extremely expensive cars increase third party insurance for everybody, including those who prefer to expend little on cars. Since they place such valuable assets on the road, they also raise the cost to others seeking to avoid damaging them. If, for instance, a driver of an old Mazda accidentally is about to make a slight dent to a mint Bugatti, she might chose a second option which will damage her old Mazda significantly, as the cost of repair might still be less that a small dent to a Bugatti. If the other car was another old Mazda, she could have made the dent and compensated the owner. By having placed the Bugatti on the road, Bob has made driving more costly for others.

\subsection{Cost Sharing}

Another factor that may be influencing our judgments when claiming that Bob is required to save the child in some of these cases is that we may think that we, or society, can and ought to step in and compensate Bob for his emergency expenditures. David Miller usefully distinguishes between immediate responsibility for bearing costs from final responsibility for bearing them (Miller 2001, 468). Perhaps considerations of undue risk in the Bugatti case are such that people will resist the idea that he should be shielded from final responsibility for bearing these losses. Let's therefore consider a case in which he has not imposed undue risk on himself:

Bob and the Avalanche: There is an unexpected avalanche that threatens to bury a child. Fortunately, Bob is able to redirect the avalanche, but the only way he can do so will lead it to the new house in which he has invested most of his savings. ${ }^{8}$

\footnotetext{
${ }^{8}$ Why does he have no insurance? Well, assume that if he had, the company would not cover damages caused by natural incidents, or that it would not cover them since Bob himself directed the avalanche towards his own new house.
} 
Would Bob be morally required to redirect the avalanche? We think this would exceed Bob's required cost to save the child if that means that he would be left to bear this cost by himself. This cost clearly exceeds what is required by Moderate, but falls within what is demanded by the SAPs. Whether Bob is morally required to redirect the avalanche seems to depend on whether he would be compensated by others in the future. If we think that Bob is required to make the rescue, we certainly ought to share the final responsibility for bearing this cost with him. We would very likely have different intuitions about cases like Bob and the Avalanche if we left individuals to shoulder alone final responsibility for assisting people in severe need when this is costly, rather than spreading it. Moreover, if we are not prepared to compensate Bob, we ought not to judge him harshly if he chooses not to redirect the avalanche. The willingness to compensate and to cover losses seems to be a requirement for demanding of others that they should carry significant losses in order to assist third parties to whom they have no special duties and to whose loses they have not contributed.

Consider again the pond case where Bob must sacrifice some of his body parts in order to save the child. Should he sacrifice a finger to prevent the child's death? Probably. What about a hand, an arm, or a leg? It just doesn't seem plausible to maintain that Bob is morally required to shoulder this much cost, even if we might praise him for doing so. What is special about these cases is not that they involve body parts but that the losses incurred cannot be easily or fully compensated for. Interestingly, there might seem to be only a weaker requirement of compensating Bob in Bob's Bugatti. The reason for this, we think, is best explained by Bob having taken undue risk when placing his savings in the Bugatti in the first place.

Earlier we suggested that the willingness to compensate and to cover losses seems to be a requirement for demanding of others that they should make significant sacrifices in order to assist third parties to whom they have no special or associative duties. This may be an interesting corollary of Murphy's fair share proposal. Unless people are willing to shoulder a fair share, they are not entitled to demand that people sacrifice more than what is required by Moderate. And no person is morally required to do so unless she can be reasonably sure that compensation will be forthcoming. But note that not even here will Murphy's compliance condition provide a complete solution. If Alice is the only person willing to compensate Bob, but there are 99 other people that could compensate him, then she is not entitled to blame Bob for not sacrificing his house if she is only willing to compensate him for her fair share-1/100 part of the amount that he is due. Alice would only be in a position to blame Bob if she would in fact share equally the cost with Bob and compensate him 50/100 part of what he is due. Were Alice to do this then both she and Bob could blame the others for not compensating them by paying their fair share.

However, even in a particular situation where Moderate demands more than what would be necessary if everyone complied, a particular individual is nevertheless be morally required to comply with Moderate should the others fail to do their fair share.

\section{Alternative Ways of Justifying Moderate}

So far, we have been arguing against the plausibility of Singer's assistance principles by appealing to people's judgments about particular cases - the preferred methodology in the Singer and Unger works under discussion. We have suggested that a moderate principle of 
assistance better captures people's judgments about these cases, but we have not offered any independent support for this principle. While providing a comprehensive justification for Moderate would require a separate paper, we gesture toward some strategies for justifying it in this section.

First, one might appeal to considerations emphasized by Garrett Cullity. Cullity maintains that it is wrong not to take the interests of others seriously (Cullity 2004). When refusing to assist another person in need, one therefore needs a reason for why one refuses, and in particular a reason that stands in relation to the severity of what is at stake for those who are in need. We think pointing to the fact that doing so will exceed moderate costs would be a plausible reason to provide to the person in need. Pointing to the loss of less than a finger will not meet this test, while the loss of a limb and perhaps also a hand would meet it. Of course, we will most likely exert our judgment about when appeal to a particular cost would fail to take the interests of others seriously in conformity with their view about what cost they believe a person ought to bear in that particular situation. It is therefore not clear to what extent this proposal can justify the content of assistance-based moral reasons.

Another way to go about giving a justification for Moderate would be to make sensible suggestions about what costs it is reasonable to expect that people should be willing to bear for others. We suggested that any given individual would be morally required to bear moderate cost relative to what is a stake for another person. This principle could be seen as striking an appropriate balance between two important values. The first value is what might be called moral equality - the idea that all people have equal (and significant) moral worth. The second value is liberty - the idea that all people have an interest in developing and pursuing a conception of the good, and the projects that pursuing it may involve. Since all people have equal worth it is reasonable to expect that all individuals would be required to make certain sacrifices to protect others from very bad things happening to them. However, because our interest in liberty is also important, we are nevertheless entitled to give considerable priority to our own concerns. Therefore, what individuals are morally required to sacrifice to help others in need is limited.

Concerns of this sort underlie Samuel Scheffler's argument that a plausible morality will grant people an "agent-centred prerogative" to pursue their own projects. According to Scheffler, the fact that "concerns and commitments are naturally generated and sustained from a person's point of view quite independently of the weight of those concerns in an impersonal ranking of overall states of affairs" (Scheffler 1982, 56) gives us reason not to require that person to choose projects and commitments "in strict proportion to the value from an impersonal standpoint of his doing so" (Scheffler 1982, 9). This also underlies much of the recent literature concerning the limits to the demands that a plausible morality ought to place on its adherents (see, for example, the collected essays in Chappell 2009).

A hypothetical contractual argument could also be developed in support of the moderate principle of assistance, but we can do no more than to provide a brief sketch of such an argument here. When engaging in contractual reasoning, a few things need to be established. First, what is the substance of the contract? In this case the agreement will be on principles of assistance - the level of sacrifice that agents will be required to make to assist others in severe need to whom they lack special or associative duties. Second, what are the interests of the parties to the contract? We will assume here that they have two interests. They are interested in security-being protected from severe harm and death. And they are interested in liberty - developing and pursuing their own conception of the good and the projects that this involves. 
In a hypothetical contract, certain information is typically concealed from the contracting parties. The information that we restrict in this case only concerns the identity of who will be put in a position where they will stand in great need of assistance and who will be in a position where they can assist. All other information remains available to the parties. In particular, they have access to the best available knowledge about their respective probabilities of being an assistor or in severe need of assistance. This is because we want the hypothetical contract to justify a particular outcome to real people with their different probabilities of ending up in need.

Clearly, the interests of the parties would pull them in different directions, and those who would have a relatively minor risk of ending up in a situation of great need would likely have very different preferences from those who have a relatively high risk of ending up in such a situation. On the one hand, interests in security (especially among those at greatest risk) would encourage the parties to adopt principles of assistance that were quite demanding, since they would know that they could depend on assistance under conditions of great need even when doing so would be costly to those who would be required to assist. On the other hand, interests in liberty (especially among those in least risk) would encourage them to reject demanding principles of assistance, since they might otherwise fear that they would have to disrupt their plans, even at great cost, whenever this would be needed to protect those in great need. For this reason, we could expect that those at relatively low risk of requiring assistance would reject very demanding principles of assistance, while those at relatively high risk of requiring assistance would reject very minimalistic principles of assistance.

Moderate is likely to benefit all contracting participants, even those who currently are at minor risk of needing help. Moderate only requires people to take on costs that seem tolerable from the perspective of actual assistors - costs they would be willing to incur or have imposed on them should this be necessary. This is important in order not to deter prospective assistors from giving assistance. By contrast, if the cost falling on prospective assistors were more than moderate, people would shun accidents and people in need. By being close to needy people they would incur very demanding duties to assist them. People are not generally willing to fulfill such requirements, and would consequently try to avoid such situations in order to avoid incurring them. The long-term probabilities of being harmed would then increase rather than fall. The contracting parties have accordingly good reason to adopt a principle of assistance that demands that people bear only moderate cost.

\section{Concluding Remarks}

We have in this article asked how much we are morally required to sacrifice to save the life of a child. We have concluded that none of the principles of assistance that has been advocated by Singer and Unger are convincing, even assuming their methodology of justifying them. Alternative assistance principles like Moderate can, when specified to take account of special cases involving voluntary imposition of undue risk and cost sharing, explain better our intuitive judgments about duties to aid people in need, and can be supported on other grounds. At the same time, however, a principle like Moderate would very likely demand much more of the affluent than what they now - unfortunately_-seem willing to sacrifice.

Acknowledgments An earlier version of this article was presented as seminars at the Australian National University and Charles Sturt University. We are grateful for comments received from audiences on those occasions, and especially to Stephanie Collins, Bashshar Haydar, Holly Lawford-Smith, Seth Lazar, Alejandra Mancilla, Leif Wenar, Luara Ferracioli and Ole Koksvik for written comments on earlier drafts. 
This article is part of a larger project on responsibilities to address poverty that has received financial support from the Australian Research Council and the Research Council of Norway.

\section{References}

Arneson R (2004) Moral limits on the demands of beneficence? In: Chatterjee DK (ed) The ethics of assistance: morality and the distant needy. Cambridge University Press, Cambridge, pp 33-58

Chappell TD (2009) The moral problem of demandingness. Palgrave, Basingstoke

Cullity G (2004) The moral demands of affluence. Clarendon, Oxford

Food and Agriculture Organization (2009) 1.02 billion people hungry. Malnutrition. News release, 19 June 2009, www.fao.org/news/story/0/item/20568/icode/en. Accessed 6 October 2010

International Energy Agency (2011) World energy outlook: access to energy. Electricity 2008. www.iea.org/ weo/electricity.asp. Accessed 7 September, 2011

Miller D (2001) Distributing responsibilities. J Polit Philos 9:453-471

Miller R (2004) Beneficence, duty and distance. Philos Public Aff 32(4):357-383

Murphy L (2000) Moral demands in nonideal theory. Oxford University Press, Oxford

Scanlon T (1998) What we owe to each other. Belknap Press of Harvard University Press, Cambridge

Scheffler S (1982) The rejection of consequentialism. Oxford University Press, Oxford

Schmidtz D (2000) Islands in a sea of obligation. Law Philos 19:683-705

Singer P (1972) Famine, affluence, and morality. Philos Public Aff 1:229-243

Singer P (1993) Practical ethics. Cambridge University Press, Cambridge

Singer P (2007) Global poverty, how demanding are our obligations? Lecture at The Massachusetts Institute of Technology, September 21, 2007. http://mitworld.mit.edu/video/487

Singer P (2009) The life you can save. Text Publishing, Melbourne

Unger P (1996) Living high and letting die. Oxford University Press, New York

United Nations Children's Fund (UNICEF) (2006) Child labour, http://www.unicef.org/protection/files/ Child_Labour.pdf. Accessed 7 September, 2011

Wenar L (2003) What we owe to distant others. Philos Polit Econ 2(3):283-304

World Health Organization and UNICEF (2010) Progress on sanitation and drinking water: 2010 update. Water and Sanitation. WHO, Geneva, pp. 6-7, www.who.int/water_sanitation_health/publications/ 9789241563956/en/index.html. Accessed 7 September, 2011. 